\title{
Peripheral Blood Stem Cell Mobilisation with Pegylated Granulocyte Colony Stimulating Factor in Children
}

\author{
Dhwanee Thakkar ${ }^{1}$, Aseem Tiwari ${ }^{1}$, Swati Pabbi ${ }^{1}$, Rohit Kapoor ${ }^{1}$, Geet Aggarwal $^{1}$, Neha \\ Rastogi $^{1}$, and Satya Yadav ${ }^{1}$ \\ ${ }^{1}$ Medanta The Medicity
}

November 2, 2020

\begin{abstract}
Aim:We report here our experience of using pegylated granulocyte colony stimulating factor (peg-GCSF) for peripheral blood stem cell (PBSC) mobilisation in children. Methods: A total of 9 children suffering from high-risk/relapsed solid tumors were mobilised with chemotherapy and peg-GCSF (100 microgram/kg single dose). Mean age was 7.7years (range 2-15 years). Results:The mean time from peg-GCSF administration to PBSC harvest was 9.7 days. Adequate stem cells (median dose 26.9 million $/ \mathrm{kg}$ ) could be harvested in all children by a single apheresis procedure. No major adverse events observed. Conclusion: It is feasible and safe to mobilise PBSC with peg-GCSF in children with cancer.
\end{abstract}

\section{Introduction}

High dose chemotherapy followed by Autologous hematopoietic stem cell transplant (HSCT) is a part of treatment regimens for many newly diagnosed and relapsed malignancies in children $(1,2)$. These autologous HSCT are most commonly performed using peripheral blood stem cells (PBSC) (2-5). Various methods are known to be effective for PBSC mobilisation including chemotherapy combined with granulocyte-colony stimulating factor (GCSF) for these patients $(2,3,5,6)$. The conventional recombinant human GCSF has a short half-life $(\sim 3.5$ hours $)$ and hence needs repeated administration which is quite painful for the child and also requires multiple hospital visits. The pegylated GCSF (Peg-GCSF) is a longer acting version of GCSF and has a half-life ranging from 15 to 80 hours after a subcutaneous injection (7-9).

Peg-GCSF is a covalent conjugate between the N-terminal methionyl residual of GCSF and mono-methoxy polyethylene glycol (Peg) moiety. Addition of Peg moiety to GCSF increases its molecular weight and size which results in decreased renal clearance by glomerular filtration. With this, the primary mode of elimination of Peg-GCSF remains to be neutrophil mediated clearance $(7,8)$. Published studies have shown that a sustained low level of GCSF is better than short pulse-like level to mobilize PBSC. Hence, Peg-GCSF, might be superior to conventional GCSF in PBSC harvest in this aspect (9).

Most of the experience with Peg-GCSF comes from its use for prophylaxis and treatment of chemotherapy associated neutropenia in children and adults as well as for PBSC mobilisation in adults (9-14). There is paucity of literature of successful use of Peg-GCSF and its appropriate dosing for PBSC mobilisation in children (1,6,15-17). We report our experience of PBSC mobilisation with Peg-GCSF in 9 children.

\section{Methods}

We carried out a retrospective analysis of hospital records of children who received Peg-GCSF for PBSC mobilization between May 2016 to September 2020 in our unit. All children received single subcutaneous dose of Peg-GCSF 100 microgram $/ \mathrm{kg}$ 24-48 hours after completion of mobilisation chemotherapy and proceeded to PBSC harvest once CD34 count was $>10 /$ microliter in the peripheral blood. All PBSC collection were 
performed on COMTEC (Fresenius Kabi, Germany) apheresis machine. The product sample was taken at the end of PBSC collection from the apheresis collection bag for enumerating CD34 count in the final product. The stem cells were cryopreserved for autologous transplant. Patients were monitored for possible adverse effects of Peg-GCSF viz. bone pain, headache, skin rash, transient hypotension, splenic enlargement, capillary leak syndrome characterized by puffiness, difficulty in breathing, decreased urine output $(1,6,13,15)$.

\section{Results}

Out of all the patients in our unit who underwent PBSC mobilization and autologous stem cell harvest, 9 received chemotherapy followed by Peg-GCSF. Male: Female ratio was 3.5:1 and the mean age was 7.7years (range 2-15 years). There were 3 cases of stage 4 Neuroblastoma and one each of metastatic Ewing's sarcoma, metastatic Germ cell tumor of ovary, recurrent anaplastic Ependymoma, relapsed Wilms tumor, relapsed Osteosarcoma and relapsed Medulloblastoma. The data on demographic profile, diagnosis, mobilisation chemotherapy, harvest details is shown in Table I. The mean time from Peg-GCSF administration to PBSC harvest was 9.7 days (range 8-12 days) and from start of mobilization chemotherapy to PBSC harvest was 12.2 days (range 10-15 days). 2 patients required one dose of GCSF boost the day before harvest. All 9 patients harvested with single apheresis procedure. The median CD34 count at the start of harvest was 203/microliter (range 30-490/microliter). The median CD34 hematopoietic stem cell count collected was 26.9 million $/ \mathrm{kg}$ (range 4.1-60 million $/ \mathrm{kg}$ ) recipient body-weight. The mean product volume collected was $152 \mathrm{ml}$ (range 70-250ml). None of the patients had any major adverse events. The median duration of follow-up for these patient's post-harvest was 6 months (range 4-38 months).

With regard to the outcome data, 1 patient couldn't reach autologous HSCT due to progression of disease. Remaining children engrafted after autologous hematopoietic stem cell infusion and all had a brisk engraftment. Neutrophil engraftment occurred at a median of 9.5 days (range 8-12 days) post autologous HSCT; Platelet engraftment occurred at a median of 11.5 days (range 10-23 days) post autologous HSCT. Transplant related mortality was nil. Two children relapsed after autologous HSCT.

\section{Discussion}

The Peg-GCSF has a longer half-life requiring a one-time administration as compared to conventional recombinant human GCSF which has a short half-life and hence requiring daily administration. This makes it more tolerable and acceptable for children (7-9). Peg-GCSF also provides a sustained drug level as compared to pulse like levels with GCSF which is more effective for PBSC mobilization (9).

Most of the experience with Peg-GCSF comes from its use for prophylaxis and treatment of chemotherapy associated neutropenia in children and adults as well as for PBSC mobilization in adults. There is paucity of literature of successful use of Peg-GCSF and its appropriate dosing for PBSC mobilization in children. From the meagre published data, we can draw conclusion that it is non-inferior to conventional GCSF with regard to efficacy and safety $(1,6,15,16)$. We have described here our experience of PBSC mobilization with PegGCSF in 9 children. Our patients received chemotherapy followed by Peg-GCSF and we found in our cohort a fairly uniform and predictable time to CD34 peak from start of chemotherapy and from the administration of Peg-GCSF. Also, we were able to harvest the desired CD34 stem cell dose in single harvest procedure for all our patients including the ones with relapsed malignancies who were heavily pretreated and hence deemed poor mobilisers. None of our patients had any major adverse event. All our patients who received autologous HSCT had a brisk and robust engraftment.

Fritsch et al. have reported a similar successful and safe harvest experience among their patient cohort which comprised of first time diagnosed solid tumor patients as well as relapsed cases. Also, no other adverse events except leukocytosis had been observed in all their patients (1). The side effect of leukocytosis was lower in those who received Peg-GCSF because Peg-GCSF has a predominant neutrophil mediated elimination and hence its clearance is self-regulating $(1,7)$. Dallorso et al found a success rate of $\sim 77 \%$ for PBSC mobilization with single dose of $100 \mathrm{mcg} / \mathrm{kg}$ of Peg-GCSF. They also found that CD34 cell levels more than 20/microliter were first observed in the peripheral blood at a median of 6 days after Peg-GCSF administration and they remained sustained above $20 /$ microliter for a median of 6 days. This points to another appealing aspect of 
Peg-GCSF that it provides a wider temporal window for planning harvest in case the peak is apparently likely to coincide with a holiday (15). Merlin et al reported a success of $60 \%$ with peg-GCSF. Target dose of 5 million $/ \mathrm{kg}$ stem cells could be collected with a single apheresis procedure in only 16 out of 26 children despite using higher dose of peg-GCSF 300 microgram $/ \mathrm{kg}$ (16). In our cohort, PBSC could be harvested successfully in $100 \%$ of patients with a single apheresis procedure. We used lower dose of peg-GCSF 100 microgram $/ \mathrm{kg}$ in all our patients. Lowest dose of stem cell collected in our cohort was 4 million $/ \mathrm{kg}$.

Peg-GCSF can circumvent the concerns of daily painful GCSF injections thereby improving the compliance and making the entire experience of autologous hematopoietic stem cell harvest more tolerable for children. Our experience highlights that its feasible and safe to mobilise PBSC with peg-GCSF in children with cancer.

Disclosure - All authors have nothing to declare. All authors have contributed to this manuscript. DT wrote manuscript, AT collected data, SP-Collected data, GA-collected data, RK-reviewed literature, NRreviewed literature, SY-wrote manuscript

\section{References}

1. Fritsch P, Schwinger W, Schwantzer G, Lackner H, Sovinz P, Wendelin G, Benesch M, Sipurzynski S, Urban C. Peripheral blood stem cell mobilization with pegfilgrastim compared to filgrastim in children and young adults with malignancies. Pediatr Blood Cancer 2010;54:134-7.

2. Cesaro S, Tintori V, Nesi F, Schiavello E, Calore E, Dallorso S, Migliavacca M, Capolsini I, Desantis R, Caselli D, Fagioli F, Luksch R, Panizzolo I, Tridello G, Prete A. A prospective study on the efficacy of mobilization of autologous peripheral stem cells in pediatric oncohematology patients. Transfusion 2013 Jul;53(7):1501-9.

3. Duong HK, Savani BN, Copelan E, Devine S, Costa LJ, Wingard JR, Shaughnessy P, Majhail N, Perales MA, Cutler CS, Bensinger W, Litzow MR, Mohty M, Champlin RE, Leather H, Giralt S, Carpenter PA. Peripheral blood progenitor cell mobilization for autologous and allogeneic hematopoietic cell transplantation: guidelines from the American Society for Blood and Marrow Transplantation. Biol Blood Marrow Transplant. 2014 Sep;20(9):1262-73.

4. Baldomero H, Gratwohl M, Gratwohl A, Tichelli A, Niederwieser D, Madrigal A, Fraundorfer K. The EBMT activity survey 2009: trends over the past five years. Bone MarrowTransplant 2011;46:485-501.

5. Pierelli L, Perseghin P, Marchetti M, Accorso P, Fanin R, Messina C, Olivieri A, Risso M, Salvaneschi L. Bosi A for Società Italiana di Emaferesi and manipolazione Cellulare (SIDEM) and Gruppo Italiano Trapianto di midollo Osseo (GITMO). Best practice for peripheral blood progenitor cell mobilization and collection in adults and children: results of a Società Italiana Di Emaferesi e Manipolazione Cellulare (SIDEM) and Gruppo Italiano Trapianto Midollo Osseo (GITMO) consensus process. Transfusion 2012;52: 893-905.

6. Cesaro S, Zanazzo AG, Frenos S, Luksch R, Pegoraro A, Tridello G, Dallorso S. A Phase II study on the safety and efficacy of a single dose of pegfilgrastim for mobilization and transplantation of autologous hematopoietic stem cells in pediatric oncohematology patients. Transfusion 2011;51:2480-7.

7. Arvedson T, O'Kelly J, Yang BB. Design Rationale and Development Approach for Pegfilgrastim as a Long-Acting Granulocyte Colony-Stimulating Factor. BioDrugs. 2015 Jun;29(3):185-98. doi: 10.1007/s40259-015-0127-4.

8. Mishra P, Nayak B, Dey RK. PEGylation in anti-cancer therapy: An overview. Asian journal of pharmaceutical s c i e n c e s ( 2016 ) 337-348

9. Kuan JW, Su AT, Leong CF. Pegylated granulocyte-colony stimulating factor versus non-pegylated granulocyte-colony stimulating factor for peripheral blood stem cell mobilization: A systematic review and meta-analysis. J Clin Apher 2017 Dec;32(6):517-542.

10. Wendelin G, Lackner H, Schwinger W, et al. Once-per-cycle Pegfilgrastim versus daily Filgrastim in pediatric patients with Ewing sarcoma. J Pediatr Hematol Oncol 2005;27:449-451.

11. te Poele EM, Kamps WA, Tamminga RY, et al. Pegfilgrastim in pedaitric cancer patients. J Paediatr Hematol Oncol 2005;27:627-629.

12. Andre N, Kababri ME, Bertrand P, et al. Safety and efficacy of PegFilgrastim in children with cancer 
receiving myelosuppressive chemotherapy. J Clin Oncol 2000;18:2522-2528.

13. Fox E, Widemann BC, Hawkins DS, Jayaprakash N, Dagher R, Aikin AA, Bernstein D, Long L, Mackall C, Helman L, Steinberg SM, Balis FM. Randomized trial and pharmacokinetic study of pegfilgrastim versus filgrastim after dose-intensive chemotherapy in young adults and children with sarcomas. Clin Cancer Res. 2009 Dec 1;15(23):7361-7.

14. Cesaro S, Nesi F, Tridello G, Abate M, Panizzolo IS, Balter R, Calore E. A randomized, non-inferiority study comparing efficacy and safety of a single dose of pegfilgrastim versus daily filgrastim in pediatric patients after autologous peripheral blood stem cell transplant. PLoS One. 2013;8(1):e53252.

15. Dallorso S, Berger M, Caviglia I, Emanueli T, Faraci M, Scarso L, Fagioli F, Haupt R. Prospective single-arm study of pegfilgrastim activity and safety in children with poor risk malignant tumours receiving chemotherapy. Bone Marrow Transplant 2008;42:507-13.

16. Merlin E, Zohar S, Jérôme C, Veyrat-Masson R, Marceau G, Paillard C, Auvrignon A, Le Moine P, Gandemer V, Sapin V, Halle P, Boiret-Dupré N, Chevret S, Deméocq F, Dubray C, Kanold J. Hematopoietic progenitor cell mobilization and harvesting in children with malignancies: do the advantages of pegfilgrastim really translate into clinical benefit? Bone Marrow Transplant 2009;43:919-25.

17. Carter T, Jensen J, Baker D, Cole G. Use of Pegylated Granulocyte Colony Stimulating Factor Mobilisation for Autologous Peripheral Blood Stem Cell Rescue- A Paediatric Experience J Pediatr Hematol Oncol _ Volume 27, Number 9, September 2005.

\section{Hosted file}

Table I.pdf available at https://authorea.com/users/357903/articles/490261-peripheral-bloodstem-cell-mobilisation-with-pegylated-granulocyte-colony-stimulating-factor-in-children 